\title{
Evaluation of the Effect of Nandrolone Decanoate on Experimental Spinal Cord Injury in Rats
}

\author{
Thyara Caroline Weizenmann ${ }^{1}$, Aline de Marco Viott ${ }^{2}$, Altina Bruna Barbosa ${ }^{3}$, Fernanda Wendt ${ }^{3}$, \\ Flávio Vieira Freitag ${ }^{3}$, José Fernando Ibãnez ${ }^{3}$, Lucas Lubasinski ${ }^{3}$, Letícia Fernanda Laube ${ }^{3}$, \\ Polyana Oliveira $^{3}$ \& Stephanie Rubbiane Carvalhal ${ }^{4}$
}

\begin{abstract}
Background: Acute spinal cord injury, a common cause of neurological dysfunction in humans and animals, impairs motor, sensory and autonomic functions and may result in permanent disability. Nandrolone decanoate (ND) is a steroid widely studied for its predominantly anabolic effect and low androgenic potential. Several researchers have described the positive interference of ND in neurological tissue, such as increased synthesis and release of neurotrophic substances, but to date no studies have evaluated the action of this steroid in acute spinal cord injury. The aim of this study was therefore to evaluate the effect of ND in rats subjected to acute spinal cord injury.

Materials, Methods \& Results: Thirty-two young adult Wistar rats (Rattus norvegicus), weighing between 240 and $260 \mathrm{~g}$, were divided into three groups. The first group (GNAN) $(n=13)$ was subjected to acute spinal cord injury and treated with $\mathrm{ND}$; the control group (GCON) $(\mathrm{n}=13)$ was subjected to spinal cord injury without treatment; and the third group (GLAM) $(n=6)$ underwent laminectomy without prior spinal cord injury, in order to control changes caused by the procedure. A 20 $\mathrm{g}$ metal device was released from a height of $25 \mathrm{~cm}$ to produce the spinal cord injury. After exposing the spinal canal, a 2-mm diameter metal rod was placed directly in contact with the spinal cord, and when the weight was released, the rod was struck, causing the spinal cord injury. An intramuscular injection of $2 \mathrm{mg} / \mathrm{kg}$ of ND was administered the immediate postoperative period. The animals were assessed to ascertain the recovery of their motor function on five occasions, namely at $24 \mathrm{~h}, 48 \mathrm{~h}, 72 \mathrm{~h}, 7$ and 14 days after undergoing spinal cord injury. This assessment was performed using the Basso, Beattie and Bresnahan (BBB) model. The animals were euthanized 14 days post-op and fragments of the spinal cord and urinary bladder were collected for histological evaluation.

Discussion: The animals subjected to spinal cord injury presented paraplegia, failing to score on the BBB scale in the first three assessments. Starting 7 days after surgery, the GNAN (0-13) and GCON (0-5) groups gradually began showing locomotor improvements, with scale variations. On day 14 after spinal cord injury, 22\% of the animals in GNAN and $11 \%$ in GCON had failed to recover their locomotor function, scoring zero on the BBB scale. After spinal cord injury, all the animals showed urine retention. The urinary function returned on average on day 5 post surgery, with no significant difference between the groups. The locomotor assessment of the animals subjected to acute spinal cord injury revealed that the injury varied in intensity in GNAN and GCON, with signs of pelvic limb paraplegia and asymmetric non-ambulatory paraparesis. Time was a determining factor in the clinical evolution of the animals, with no evidence of the influence of ND. The histological findings revealed variations in the intensity of the injury, with a tendency for lower intensity in the cranial and epicentral segments of the lesion in the animals subjected to ND treatment, albeit without statistically significant evidence $(P \geq 0.05)$. The spinal cord assessments of the GLAM group indicated that the surgical procedure did not cause histological alterations, since the normal architecture of the neural tissue was preserved. The histopathological evaluations of the urinary bladder revealed an inflammatory response characterized by lymphohistiocytosis and neutrocytosis in the animals of GNAN and GCON, without interference of ND in the change $(P \geq 0.05)$. The method to elicit spinal cord injury reproduced functional, sensory and motor incapacity heterogeneously in rats. In the dose evaluated here, ND did not significantly influence the return of locomotor function and the intensity of spinal cord histopathological alterations.
\end{abstract}

Keywords: animal models, spinal canal, neuroprotective drugs, steroids.

DOI: $10.22456 / 1679-9216.98190$

Received: 18 July 2019

Accepted: 12 November 2019

Published: 5 December 2019

${ }^{1}$ Departamento de Ciência Animal, Universidade Estadual de Londrina (UEL), Londrina, PR, Brazil. ${ }^{2}$ Departamento de Ciências Veterinárias, Universidade Federal do Paraná (UFPR), Palotina, PR. ${ }^{3}$ Departamento de Ciências Veterinárias \& ${ }^{4}$ Departamento de Ciências Biológicas, UFPR, Curitiba, PR. CORRESPONDENCE: T.C. Weizenmann [thyarac@hotmail.com] \& A.M. Viott [viott@ufpr.br]. Departamento de Ciência Animal - UEL. Rodovia Celso Garcia Cid, km 445. CEP 86057-970 Londrina PR, Brazil. 


\section{INTRODUCTION}

Spinal cord injuries cause neurological disorders that impair motor, sensory and autonomic functions, and may result in permanent loss of neurological function $[6,16]$. Current treatment options include surgical interventions for spinal cord decompression and stabilization. The goal of treatment is to enable neurological recovery in cases where the magnitude of the primary injury is below the threshold that renders it irreversible [1,2].

Acute spinal cord injury leads to neurological deficits primarily due to direct interruption of the neural pathways, and to secondary alterations resulting in low local blood flow, ischemia, and neuronal death [1]. The process of neurological recovery depends on synaptic plasticity in preexisting neuronal circuits, and on the formation of compensatory neural pathways [2]. Researchers have pointed out the need for studies to better characterize the mechanisms of neuronal protection, axonal regeneration and functional recovery after acute spinal cord injury [2,23].

Anabolic androgenic steroids are synthetic derivatives of the male hormone testosterone, one of whose main representatives is nandrolone decanoate (ND) [12]. Experiments with rats and rabbits subjected to peripheral nerve injury revealed that treating them with ND led to better motor and sensory recovery $[13,22]$. In view of the potential benefits of ND, the aim here was to make a histological evaluation of spinal cords and urinary bladders of Wistar rats subjected to acute spinal cord injury and treated with ND.

\section{MATERIALS AND METHODS}

\section{Animals and groups}

Thirty-two young adult male Wistar rats (Rattus novergicus), weighing between 240 and $260 \mathrm{~g}$, were supplied by the Central Vivarium of the Federal University of Paraná (UFPR) for this study. The experiment was approved by the Ethics Committee on Animal Use (CEUA) of UFPR, under Protocol No. 23075.211646/2017-07.

The animals were divided into three groups: one group subjected to acute spinal cord injury and treated with ND (GNAN, n=13); a control group subjected to spinal cord injury without treatment (GCON, $\mathrm{n}=13$ ); and a third group subjected to laminectomy without spinal cord injury (GLAM, n=6).
Surgical procedure and postoperative care

The preanesthetic medication consisted of a combination of $2 \mathrm{mg} / \mathrm{kg}$ of midazolam $\left(\text { Dormiun }^{\circledR}\right)^{1}$ and $3 \mathrm{mg} / \mathrm{kg}$ of morphine $\left(\text { Dimorf }^{\circledR}\right)^{2}$. Anesthesia was maintained with isoflurane (Isoflurano $\left.{ }^{\circledR}\right)^{3}$ infusion in $100 \%$ oxygen. After shaving, local blockage and surgical-site antisepsis, a $2 \mathrm{~cm}$ surgical incision was made along the dorsal midline to expose the spinous processes of $\mathrm{T} 8$ to T12. The subcutaneous tissue and muscles were separated. The T10 spinous process and the distal half of the T9 spinous process were removed. A laminectomy was performed to expose the dura mater, in order to insert the metal rod of the impact device. This device, which releases a weight of $20 \mathrm{~g}$ from a height of $25 \mathrm{~cm}$, has a rod head diameter of $2 \mathrm{~mm}$ (Figure 1). After placing the animal at the center of the impact device, the rod was inserted into the exposed spinal segment and the weight was released. The spinal cord injury was inspected, and hemostasis was performed whenever bleeding was found, after which the muscles and skin were sewn up in a simple interrupted pattern using non-absorbable nylon 4-0 suture $\left(\mathrm{Nylon}^{\circledR}\right)^{4}$.

The animals were kept warm until they recovered their minimum temperature of $36^{\circ} \mathrm{C}$. They were then placed in boxes and monitored for urinary function, with bladder compression applied every six hours until complete recovery. The analgesic protocol was $5 \mathrm{mg} / \mathrm{kg} / \mathrm{b}$.i.d. of morphine (Dimorf $\left.{ }^{\circledR}\right)^{2}$ administered intramuscularly for three days. As a prophylactic antibiotic, $10 \mathrm{mg} / \mathrm{kg} / \mathrm{s} . i . d$. of enrofloxacin (Baytril $\left.5 \%{ }^{\circledR}\right)^{5}$ was administered intramuscularly for five days. All the animals of this study received this treatment in order to avoid bias in the evaluations. The animals of GNAN received a single dose of $2 \mathrm{mg} / \mathrm{kg}$ of ND $\left(\text { Deca-Durabolin }{ }^{\circledR}\right)^{6}$ administered intramuscularly immediately post-injury.

\section{Motor assessment}

The motor assessment was performed after $24 \mathrm{~h}, 48 \mathrm{~h}, 72 \mathrm{~h}, 7$ and 14 days postinjury, using the BBB locomotor rating scale [3]. Total loss of motility of the pelvic limbs $24 \mathrm{~h}$ after surgery was a criterion of inclusion of the animals in the study. The animals were filmed and evaluated in an open field $(0.8 \mathrm{~m} \mathrm{x}$ $1.5 \mathrm{~m}$ ) for $5 \mathrm{~min}$.

\section{Euthanasia and preparation of biological samples}

The rats were euthanized 14 days after undergoing spinal cord injury. They were first anesthetized 
in a closed chamber system, using gauze soaked in sevoflurane $\left(\text { Anesevo }{ }^{\circledR}\right)^{3}$, causing rapid and effortless loss of consciousness. Then, after deep anesthesia was confirmed, the animals were decapitated. Necropsy was then performed and samples were collected from the spinal cord and urinary bladder. Spinal cord fragments were taken from the epicenter, and from $3 \mathrm{~mm}$ in the cranial and $3 \mathrm{~mm}$ in the caudal direction of the lesion. The fragments were prepared using the hematoxylin and eosin (HE) staining protocol.

\section{Statistical analysis}

The GLAM group presented no spinal or bladder alterations and, in view of the absence of variability (constant parameter), its inclusion in the statistical analysis was considered unnecessary. The data were statistically evaluated using R 3.5.0 software and the nparLD package. The test results were considered statistically significant when the level of significance ( $P$ value) was less than $0.05(P \leq 0.05)$.

The GNAN and GCON groups were evaluated and compared to each other. The recovery of spontaneous micturition was analyzed using the Mann-Whitney U-test. The temporal evolution of the BBB score was evaluated by means of the nonparametric ANOVA test. The variable of histological alteration of the bladder was compared using Fischer's exact test, and the groups were compared using the Mann-Whitney U-test.

\section{RESULTS}

\section{Mortality rate in the study}

Two GCON animals died in the intraoperative period and two GNAN animals died $24 \mathrm{~h}$ after injury, corresponding to a mortality rate of $15.39 \%$. The possible cause of death of these animals during the procedure was neurogenic pulmonary edema due to pulmonary congestion, found at necropsy. GNAN rats showed no macroscopic alterations at necropsy, and since the cause of death could not be clarified, these animals were excluded from the study.

\section{Locomotor evaluation}

The locomotor assessment consisted of monitoring the animals on five different occasions ( $24 \mathrm{~h}, 48$ h, 72 h, 7 and 14 days post-surgery). Four animals were excluded from the study, two from the GNAN group and two from the GCON, because they did not present a zero score on the BBB scale in the first locomotor evaluation after spinal cord injury. Thus, 24 animals remained in the study, nine each in the GNAN and GCON groups, and six in the GLAM group.

The GLAM group scored 21 points on the BBB scale in the five locomotor assessments. As for the animals subjected to spinal cord injury, all of them scored zero points on the BBB scale in the first three assessments. Starting from the fourth assessment, on day 7 after surgery, the animals presented a variety of BBB scores. Partial motor recovery started on average seven days after injury, represented by $66.67 \%(n=6)$ of the individuals of both groups, with varying BBB scores. On day 14 , only $22 \%$ of the animals $(n=2)$ of the experimental group and $11.11 \%(n=1)$ of the control group had not recovered their locomotor function, scoring zero on the BBB scale. The statistical difference between the groups was not significant $(P \geq 0.05)$. Table 1 describes the results of the locomotor assessment.

\section{Evaluation of the recovery of spontaneous micturition}

After undergoing spinal cord injury, all the animals $(n=18)$ showed urine retention, and bladder compression was performed every $6 \mathrm{~h}$ until recovery of the function. This occurred on average five days after surgery, starting on day 2 in both groups and ending on day 9 in GNAN and day 10 in GCON, with no statistically significant difference between the groups $(P \geq 0.05)$.

\section{Histological evaluation of the spinal cord}

Histological changes in the spinal cord were evaluated based on criteria for spinal cord injury described in the literature, such as hemorrhage, chromatolysis, spongiosis, neuronal necrosis, astrocytosis and astrogliosis, Gitter cells, leuko- and poliomyelomalacia, identified in three segments of spinal cord, i.e., cranial, epicentral and caudal to the lesion. Scores were attributed according to the intensity of the lesion, as absent, mild (+, less than $30 \%$ of the affected area), moderate ( ++ , from 30 to $70 \%$ of the affected area), and marked (+++, more than $70 \%$ of the affected area) [11]. In the histological evaluation of spinal cord, all the evaluated segments revealed absence of hematoma or any hemorrhagic alterations. Axonal injury was detected with central chromatolysis, spongiosis and neuronal necrosis. These changes were less intense in the cranial and epicentral segments of the lesion in the GNAN group $(P \geq 0.05)$. 
All the animals that underwent spinal cord injury presented varying degrees of astrocytosis and astrogliosis, which were less intense in the cranial and epicentral segments of the lesion in GNAN $(P \geq 0.05)$.

The epicentral portion of the lesion showed loss of normal architecture, with areas of white and gray matter indicative of necrosis, proliferation of Gitter cells and digestion chambers occurring frequently in all the animals of both groups. These cells were less intense in the cranial and epicentral segments of the lesion in GNAN. Leuko- and poliomyelomalacia intensity was also lower in the cranial segment of the GNAN animals. Moreover, polio-myelomalacia was also less intense in the epicentral portion of the lesion in the animals of this group $(P \geq 0.05)$.

In this study, although individual analyses revealed lower intensity of lesions in GNAN, the injury sites and characteristics evaluated showed no significant differences between the groups $(P \geq 0.05)$.

\section{Histological evaluation of the urinary bladder}

The urinary bladder was assessed qualitatively to determine the absence or presence of inflammatory infiltrate and hemorrhage. Histopathological examination revealed inflammatory tissue response characterized by lymphohistiocytosis and neutrocytosis in the animals of both groups subjected to spinal cord injury. The frequency of cystitis was $77.8 \%$ in the GNAN group and $55.6 \%$ in GCON, with no significant difference between the groups $(P \geq 0.05)$.

\section{DISCUSSION}

Spinal cord injury was produced by applying $20 \mathrm{~g}$ of weight with an impact force of $400 \mathrm{~g} / \mathrm{cm}^{3}$ on the spinal cord, as described in the literature [10]. The model used here was effective in causing spinal cord injury, which was confirmed immediately after the trauma by the presence of edema, hemorrhage and loss of integrity of the tissue architecture. The first sign of spinal cord injury is edema of the nervous tissue, caused by capillary extravasation and parenchymal hemorrhage of white matter [23].

The animals subjected to spinal cord injury showed a mortality rate of $15.39 \%$, and one of the causes was neurogenic pulmonary edema. The literature describes different mortality rates, with high rates closely related to the method of injury, impact intensity and severity of injury, and the main causes of death are neurogenic pulmonary edema and urine retention [8]. Neurogenic pulmonary edema can occur within $72 \mathrm{~h}$ after injury, due to excessive sympathetic activation and blood redistribution to the pulmonary vascular bed [8]. Patients with spinal cord trauma in the $\mathrm{T} 3$ to $\mathrm{L} 3$ region suffer from urine retention due to their inability to empty the bladder [9]. In this study, all the animals subjected to spinal cord injury underwent urine retention, with recovery of the function varying over time. No evidence was found of the influence of nandrolone decanoate on the time elapsed until the recovery of spontaneous urination.

Table 1. Representation of the median, minimum and maximum scores, and confidence interval (CI) obtained from the statistical analysis on the BBB scale, at the five occasions of locomotor evaluation of the GNAN and GCON groups.

\begin{tabular}{ccccc}
\hline & & Median & Min-Max & CI \\
\hline GCON & BBB 24 h & 0 & $0-0$ & 0.0 \\
& BBB 48 h & 0 & $0-0$ & 0.0 \\
& BBB 72 h & 0 & $0-0$ & 0.0 \\
& BBB 7 days & 3 & $0-13$ & 7.0 \\
& BBB 14 days & 7 & $0-20$ & 11.0 \\
\hline GNAN & BBB 24 h & 0 & $0-0$ & 0.0 \\
& BBB 48 h & 0 & $0-0$ & 0.0 \\
& BBB 72 h & 0 & $0-0$ & 0.0 \\
& BBB 7 days & 1 & $0-15$ & 1.0 \\
& BBB 14 days & 7 & $0-20$ & 13.0 \\
\hline
\end{tabular}

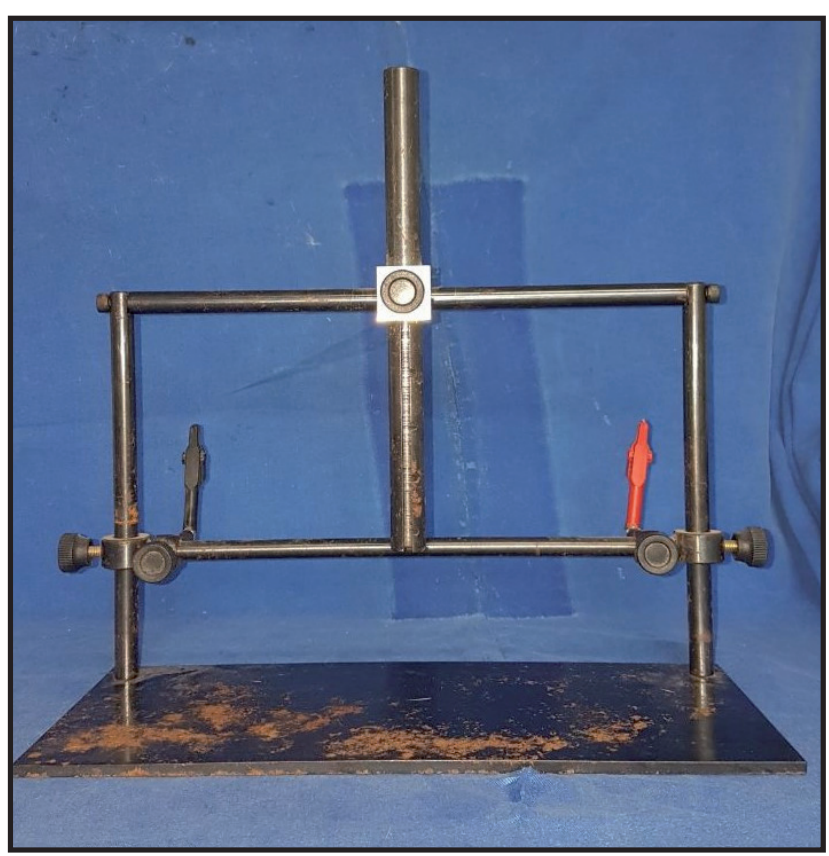

Figure 1. Impact device employed to produce experimental spinal cord injury in rats. 
In the first three assessments, all the animals of this study presented paraplegia, scoring zero on the BBB scale. Starting from the fourth assessment, the animals presented a variety of scores, with signs of pelvic limb paraplegia, and asymmetric non-ambulatory paraparesis. Experimental studies of spinal cord injury have described the occurrence of variations in neurological deficits in injuries caused by the same weight, possibly due to individual anatomical variations $[18,20]$.

The BBB locomotor rating scale, which was used on patients subjected to laminectomy, revealed that the surgical technique does not promote locomotor deficits, since the animals in the group had the highest BBB score on the five occasions of locomotor evaluation. Both groups of animals subjected to spinal cord injury showed gradual improvement of locomotor function. Spontaneous recovery after spinal trauma has been reported, and stems from the functional regeneration of axons that have remained intact inside damaged tissue [20]. The use of ND was not found to influence the BBB scores in this study. However, time was a determining factor in the evolution, with a significant improvement in the BBB score throughout the experiment, regardless of the treatment.

The animals of both groups showed histological changes in the urinary bladder characterized by lymphohistiocytosis. The use of ND did not show direct antiinflammatory action in the presence of altered bladder function.

Histological assessments of spinal cord segments revealed the absence of hematoma or any hemorrhage-induced alterations. Hemorrhagic areas are replaced by cystic cavitation surrounded by reactive astrocytes, beginning five days after injury, and act as a potent inhibitor of neuronal regeneration [17,19].

All the spinal cord segments showed loss of neuronal integrity, indicated by the presence of central chromatolysis and neuronal necrosis. Activation of phagocytic cells, such as Gitter cells, precedes the astrocytic reaction, and is involved in the inflammatory response [14]. Despite the tendency for lower intensity of Gitter cells and astrocytosis in the experimental group, the influence of ND in limiting these alterations could not be confirmed.

Greater intensity of the lesion was found in the epicentral portion of the injury, which decreased in the caudal and cranial segments in all the animals with spinal cord injury. The group treated with ND showed lower intensity of lesions in the cranial and epicentral segments of the injury, but this tendency did not represent a statistically significant difference. Similar changes were described in a study with estrogen in spinal cord injury in rats [21]. There are no studies involving the use of ND to treat acute spinal cord injury.

The absence of a significant influence of nandrolone decanoate on the intensity of the histology alterations in spinal cord evaluated here may be attributed to the small number of animals or the nonexistence of a real difference. This justifies an increase in the experimental sample size to confirm individual tendencies that were not significant [7]. Moreover, to ensure more detailed results, the ideal situation would be to extend the period of observation, since time was a determining factor for the recovery of the animals in this study.

The dose of ND used here was $2 \mathrm{mg} / \mathrm{kg}$, administered intramuscularly, as described in the literature [15]. However, the optimal dose to elicit nerve regeneration has not yet been determined, and suggestions for its use for different purposes range from 1 to $10 \mathrm{mg}$ / $\mathrm{kg}$ [13]. Adverse effects caused by ND are often related to dosage forms, particularly dose and frequency [4]. Experimental studies with rats exposed to exogenous testosterone describe changes in social behavior and increased aggressiveness [5]. No such changes were detected in this study, possibly because the drug was administered in a single and low dose.

Experimental models have been used to gain insight into the pathophysiology of spinal cord injury $[3,6]$. The animal of choice for this study was the rat, because it was considered the best experimental model in previous analyses, due to the characteristics of its spinal cord [7].

Despite no evidence of ND interference in the clinical evolution of the animals, relevant histological changes were observed in the treatment group, and considering this promising neuroprotective properties, further studies are suggested, which may highlight ND as a potential therapy for acute spinal cord injury in animals and humans.

\section{CONCLUSIONS}

The model of spinal cord compression injury reproduced severe functional, sensory and motor impairment heterogeneously in rats. In the evaluated dose, 
ND did not affect the recovery of locomotor function in rats subjected to spinal cord injury. Time was the determining factor for recovery of locomotor function. ND may interfere with the progression of secondary injuries resulting from acute spinal cord trauma, and therefore the need for further investigation of the mechanisms involved in neuroprotection, which may result in therapies that enable the recovery of animals and humans with spinal cord injury.

\section{MANUFACTURERS}

${ }^{1}$ União Química - Farmacêutica Nacional S/A. São Paulo, SP, Brazil. ${ }^{2}$ Cristália Produtos Químicos Farmacêuticos Ltda. Itapira, SP, Brazil. ${ }^{3}$ Instituto Biochimico Indústria Farmacêutica Ltda. Itatiaia, RJ, Brazil.
${ }^{4}$ Shalon Suturas. São Luís de Montes Belos, GO, Brazil.

${ }^{5}$ Bayer. São Paulo, SP, Brazil.

${ }^{6}$ Organon do Brasil Indústria e Comércio Ltda. São Paulo, SP, Brazil.

Funding. The authors gratefully acknowledge CAPES (Brazil's Federal Agency for the Support and Improvement of Higher Education) for its financial support through a research grant (Financing 001).

Ethical approval. This research project was approved by the Ethics Committee on Animal Use (CEUA) of the Federal University of Paraná, Protocol No. 23075.211646/2017-07.

Declaration of interest. The authors report no conflicts of interest. The authors alone are responsible for the content and writing of this paper.

\section{REFERENCES}

1 Ahuja C.S., Nori S., Tetreault L., WilsonJ., Know B., Harrop J., Choi D. \& Fehlings M.G. 2017. Traumatic spinal cord injury - repair and regeneration. Neurosurgery. 80(3S): S9-S22.

2 Baklaushev V.P., Bogush V.G., Kalsin V.A., Sovetnikov N.N., Samoilova E.M., Revkova V.A., Sidoruk K.V., Konoplyannikov M.A., Timashev P.S., Kotova S.L., Yushkov K.B., Averyanov A.V., Troitskiy A.V. \& Ahlfors J.E. 2019. Tissue engineered neural constructs composed of neural precursor cells, recombinant spidroin and PRP for neural tissue regeneration. Scientific Reports. 9(1): 3161.

3 Basso D.M., Beattie M.S. \& Bresnahan J.C. 1995. A sensitive and reliable locomotor rating scale for open field testing in rats. Journal of Neurotrauma. 12(1): 1-21.

4 Brower K.L. 2002. Anabolic steroid abuse and dependence. Current Psychiatry Reports. 4(5): 377-387.

5 Busardò F.P., Frati P., Di Sanzo M., Napoletano S., Pinchi E., Zaami S. \& Fineschi V. 2015. The impact of nandrolone decanoate on the central nervous system. Current Neuropharmacology. 13(1): 122-131.

6 Caliskan M., Simsek S., Vural S.A. \& Besaltl O. 2016. Comparison of etanercept, etomidate and erythropoietin and their combinations in experimentally-induced spinal cord injury. Turkish Neurosurgery. 26(6): 930-936.

7 Carvalho K.A.T., Vialle E.N., Moreira G.H.G., Francisco J.C., Simeoni R.B., Oliveira L., Cunha R.C., GuaritaSouza L.C., Olandoski M. \& Vialle L.R.G. 2007. Avaliação funcional da terapia autóloga de células derivadas medula óssea, fração mononuclear no trauma crônico da medula espinal - modelo experimental em animais. Jornal Brasileiro de Transplantes. 10(1): 664-668.

8 Chu R., Wang J., Bi Y. \& Nan G. 2018. The kinetics of autophagy in the lung following acute spinal cord injury in rats. Spinal Journal. 18(5): 845-856.

9 Dinh A., Davido B., Duran C., Bouchand F., Gaillard J.L., Even A., Denys P., Chartier-Kastler E. \& Bernard L. 2019. Urinary tract infections in patients with neurogenic bladder. Médecine et Maladies Infectieuses. S0399-077X(18): 30613-30619.

10 Ducker T.B., Kindt G.W. \& Kempe I.G. 1971. Pathological findings in acute experimental cord trauma. Journal of Neurosurgery. 35(6): 700-708.

11 Finkelstein S.D., Gillespie J.A., Markowitz R.S., Johnson D.D. \& Black P. 1990. Experimental spinal cord injury: qualitative and quantitative histopathologic evaluation. Journal of Neurotrauma. 7(1): 29-40.

12 Gao W., Bohl C.E. \& Dalon J.T. 2005. Chemistry and structural biology of androgen receptor. Chemical Reviews. 105(9): 3352-3370.

13 Ghizoni M.F., Bertelli J.A., Grala C.G. \& Da Silva R. 2013. The anabolic steroid nandrolone enhances motor and sensory functional recovery in rat median nerve repair with long interpositional nerve grafts. Neurorehabil Neural Repair: Sage Journals. 27(3): 269-276. 
14 Graeber M.B. \& Streit W.J. 1990. Microglia: immune network in the CNS. Brain Pathology. 1(1): 2-5.

15 Ibanez J.F., Silva T.S. \& Pontes D.R. 2003. Uso de decanoato de nandrolona (Decadurabolin) como estimulante da proliferação óssea em cães com consolidação retardada. Brazilian Journal of Veterinary Research and Animal Science. 40(supl): 229-230.

16 Jutzeler C.R., Streijger F., Aguilar J., Shortt K., Manouchehri N., Okon E., Hupp M., Curt A., Kwon B.K. \& Kramer J.L.K. 2018. Sensorimotor plasticity after spinal cord injury: a longitudinal and translational study. Annals of Clinical and Translational Neurology. 6(1): 68-82.

17 Loane D.J. \& Byrnes K.R. 2010. Role of microglia in neurotrauma. Neurotherapeutics. 7(4): 366-377.

18 Panjabi M.M. \& Wrathall J.R. 1988. Biomechanical analysis of experimental spinal cord injury and functional loss. Spine. 13(12): 1365-1370.

19 Shen Y. 2014. Traffic lights for axon growtu: proteoglycans and their neuronal receptors. Neural Regeneration Research. 9(4): 356-361.

20 Song W., Song G., Zhao C., Li X., Pei X., Zhao W., Gao Y., Rao J.S., Duan H. \& Yang Z. 2018. Testing pathological variation of white matter tract in adult rats after severe spinal cord injury with MRI. BioMed Research International. 4068156: 1-13.

21 Sribnick E.A., Samantaray S., Das A., Smith J., Matzelle D.D., Ray S.K. \& Banik N. L. 2010. Postinjury estrogen treatment of chronic spinal cord injury improves locomotor function in rats. Journal of Neuroscience Research. 48(8): 1738-1750.

22 Vita G., Dattola R., Girlanda P., Oteri G., Lo Presti F. \& Messina C. 1983. Effects of steroid hormones on muscle reinnervation after nerve crush in rabbit. Experimental Neurology. 80(2): 279-287.

23 Zhang X., Liu C.B., Yang D.G., Qin C., Dong X.C., Li D.P., Zhang C., Guo Y., Du L.J., Gao F., Yang M.L. \& Li J.J. 2019. Dynamic changes in intramedullary pressure 72 hours after spinal cord injury. Neural Regeneration Research. 14(5): 886-895. 